Phenomenology in Nursing Studies: New perspectives

\title{
ABSTRACT:
}

Nursing studies have for decades drawn on the philosophical tradition of phenomenology when developing their own methodology and theoretical foundation. This use and application of phenomenology has, however, not been met with universal approval. One prominent and persistent opponent has been John Paley, who has sent a clear message to the nursing community: If you are looking for philosophical inspiration or methodological guidance, do not look to phenomenology.

As we argue in the article, in formulating his criticism, Paley completely overlooks a rich tradition of applied phenomenology that dates back to the beginning of the $20^{\text {th }}$ century and which has undergone a momentous revival during the last 20-25 years. That Paley seems oblivious to this tradition is one thing. What is more astonishing is that this also holds true for the vast majority of those scholars working within nursing science who happens to be interested in phenomenology.

The aim of this article is, first, to present and consider Paley's criticism in some detail and, then, to discuss some of the significant applications of phenomenology that have often been overlooked by qualitative researchers. As has been amply demonstrated over the years, phenomenology can not only make a difference in the handling, analysis, and interpretation of the available data, but also, in how the data are obtained in the first place, for instance, through special interview techniques. We will first consider some central figures in classical phenomenological psychology and phenomenological psychiatry, and then present some of the more recent developments in cognitive science. We will next discuss three concrete cases that demonstrate how phenomenology has been applied in clinical work with patients with schizophrenia, cerebral palsy, and hemispatial neglect.

Our main message to qualitative researchers interested in phenomenology is the following. You should also start to consider and draw inspiration from the way in which phenomenology has been applied outside of the domain of qualitative research. There are very successful applications of phenomenology to be found elsewhere, applications that can offer substantial theoretical and methodological support to qualitative researchers. Relevant resources 
include classical phenomenological psychology, classical and contemporary phenomenological psychiatry, and contemporary discussions of naturalized phenomenology.

What is already known about the topic?

- Nursing studies have for decades drawn on the philosophical tradition of phenomenology when developing their own methodology and theoretical foundations

- This use of phenomenology has recently been heavily criticized by John Paley

- The future of phenomenology in nursing studies is currently being questioned

What this paper adds

- New perspectives on applying phenomenology in nursing studies, which dispute Paley's dismissal of phenomenology

- Instructive examples of applied phenomenology that have been ignored, but which offer substantial theoretical and methodological support to nurses and qualitative researchers - Concrete cases that demonstrate how phenomenology has been applied in clinical work - Criteria and advice for value-assessment of the application of phenomenology

Nursing studies have for decades drawn on the philosophical tradition of phenomenology when developing and securing their own methodology and theoretical foundations. This use and application of phenomenology has, however, not been met with universal approval. One prominent and persistent opponent has been John Paley, whose criticism has primarily targeted the work of Giorgi, Smith, and van Manen. Paley has sent an unequivocal message to qualitative researchers in general and to the nursing community in particular: If you are looking for philosophical inspiration or methodological guidance, do not look to phenomenology (Paley 1997, 2005, 2017).

Paley's message has resonated through nursing studies, to such a degree that some have even started to ask the question, "Is there nursing phenomenology after Paley?” (Petrovskaya 
2014). If qualitative research in general and nursing studies in particular want to continue to employ phenomenology, how then should they proceed? What is the best way to apply phenomenology? Some answers to these questions can be found in resources that Paley completely overlooks. There is a long and rich tradition of applied phenomenology dating back to the beginning of the $20^{\text {th }}$ century, which has undergone a momentous revival during the last 20-25 years. That Paley seems oblivious to this tradition is one thing. What is more astonishing is that this also holds true for the vast majority of those scholars working within nursing science who happens to be interested in phenomenology.

The aim of this article is, first, to present Paley's criticism in some detail and, then, to

discuss some of the significant applications of phenomenology that tend to be overlooked by qualitative researchers. We will consider some central figures in classical phenomenological psychology and phenomenological psychiatry, and also discuss some more recent developments in cognitive science. We will next present three concrete cases that demonstrate how phenomenology has been applied in clinical work with patients with schizophrenia, cerebral palsy, and hemispatial neglect. Our overall hope is that nurses interested in phenomenologically inspired qualitative research will start to look beyond the accounts offered by Giorgi, Smith, and van Manen and also consider some of the resources we discuss below. As will become clear, our aim is not to cast phenomenology as a qualitative research method, but to argue that phenomenology when properly applied can nevertheless offer qualitative researchers substantial theoretical and methodological support.

\section{Paley's criticism}

For many years, Paley has been an ardent critic of phenomenology as a qualitative research method. He has distinguished the classical philosophical phenomenology that we find in Husserl and Heidegger from what he calls the 'philosophy of nurse-phenomenology' (Paley 2005: 106107, cf. Paley 2017: 2), which refers to the various ontological and epistemological claims made by nurses who are inspired by phenomenology. Paley has argued that 'nurse-phenomenology' has little to do with classical phenomenology despite its frequent appeal to it. Indeed, he has accused nurses of mostly misinterpreting the philosophical ideas and of relying on second-hand sources, rather than going directly to the primary sources themselves (Paley 1997: 187-188). But Paley's 
recommendation has not been that nurses should simply become more familiar with the philosophy they are basing their research on, but rather that they should abandon their attempts to ground their research on phenomenological philosophy altogether (Paley 1997: 192).

In his most recent and most comprehensive attack on phenomenology, the book Phenomenology as Qualitative Research: A Critical Analysis of Meaning Attribution, Paley argues that a critical assessment of phenomenology as a qualitative research method should be conducted without engaging at all with phenomenological philosophy, since the "convolutions" of the latter "can only be a distraction" (Paley 2017: 3). Indeed, according to Paley, Husserl "can be almost wilfully obscure” (Paley 2017: 7). Paley then commences a critical assessment of three leading approaches to phenomenology as a qualitative research method, namely Amedeo Giorgi's Descriptive phenomenological method, Jonathan Smith's Interpretative phenomenological analysis (IPA), and Max van Manen's Hermeneutical phenomenology. All three enjoy wide popularity and are routinely referenced and used in nursing studies and by qualitative researchers in general. As is also well known, all three differ in their methodological recommendations and in how they apply phenomenology. There is, moreover, an ongoing controversy about how narrowly or broadly one should define what counts as phenomenological. Is it sufficient simply to consider the first-person perspective of the agent/patient/client in order to make the approach in question phenomenological? Must phenomenological qualitative research embrace and adopt part of Husserl's philosophical method, in particular his notions of epoché and reduction, or can it dispense with those notions and instead draw methodological inspiration from a mixture of different phenomenological authors? Should phenomenological qualitative research remain purely descriptive and seek to disclose essential structures, or should it rather employ interpretation and focus on the particularity of individual persons?

Paley considers the disagreement between a more descriptive and a more interpretative approach to phenomenology ridiculous. In his view, there are far more important things to do than to describe and interpret, namely to explain, theorise, test, and evaluate (Paley 2017: 30). Paley also wonders why phenomenological qualitative researchers are forbidden from taking an interest in causes, models, and mechanisms, and why they are committed to a flat reductionism that rules out the existence of causal mechanisms and takes the world to consist of nothing but phenomena to be described or interpreted (Paley 2017: 30). We will return to this specific criticism later on. It is, in any case, not Paley's most decisive reproach. After having discussed Giorgi, Smith, and van 
Manen in quite some detail, Paley ultimately concludes that all three fail to provide clear definitions of the central concepts they use, that their approaches lack methodological rigour, employ arbitrary procedures, and are thoroughly permeated by personal idiosyncrasies (Paley 2017: 28, 147).

Paley's book has subsequently been applauded for having revealed the "emperor's lack of clothing and pushed him into the spotlight for all to see" (Watson 2017). And, in his blurb for Phenomenology as Qualitative Research, Martin Lipscomb has commended it as required reading for "any nurse contemplating undertaking a phenomenological study" and as a book whose influence "will ripple through nursing research and education for many years to come."

Our aim in the following is to show that Paley's assessment of phenomenology is unwarranted. This does not mean, however, that we intend to defend the qualitative researchers he is criticizing. Although his reading of Giorgi, Smith, and van Manen is very uncharitable, Paley must also be commended for highlighting some serious problems and weaknesses in the proposals he is discussing. ${ }^{1}$ We argue, however, that Paley's dismissal of the idea that nurses and other health care professionals might learn something useful from phenomenology is premature since there are other more fertile resources than Giorgi, Smith and van Manen to draw from, if one is interested in applying phenomenology to qualitative research-resources that Paley ignores.

Before moving on to our real target, a few final remarks about Paley. As already noted, Paley has been quick to criticize the manner in which Husserl's phenomenology has been misinterpreted and misappropriated by nurses. One does not have to look beyond Paley's own texts to find examples of such misinterpretations, however. A good deal of what Paley has to say about phenomenology is simply wrong. It is perhaps not entirely coincidental, that the most unreserved endorsements of Paley's work have come from researchers with little documented knowledge of that tradition. Since our aim in the present article is different, we will not list all the mistakes, but here are a few: It is a mistake to claim, as Paley does, that the performance of the epoché (which Paley erroneously thinks is simply another name for the phenomenological reduction) immediately removes us from the social world (Paley 1997: 188). When Paley claims that Husserl tried to "break out of experience (into the realm of pure consciousness) through the phenomenological

\footnotetext{
${ }^{1}$ One of us has previously criticized Giorgi, Smith and van Manen in some detail (see Zahavi 2018, 2019, in press).
} 
reduction” (2013: 148), or when he claims that Husserl's phenomenology is solipsistic in nature and that it seeks to explain the external world by appealing to a pure and totally isolated individual consciousness (Paley 1997: 190; Paley 2017: 65), he is also making claims that are contradicted by contemporary Husserl scholarship. ${ }^{2}$

\section{Classical phenomenological psychology and psychiatry}

If we now shift focus and move from the current debate between Paley and the qualitative researchers to the historical sources, we will see that Husserl's lectures and writings already early on became a source of inspiration for psychologists and psychiatrists (cf. Spiegelberg 1972). One seminal psychologist was David Katz (1884-1953). Katz was deeply interested in human experience and argued that one should employ the phenomenological method if one wanted to disclose and do justice to the manifold of qualitative phenomena (Katz 1999: 5). Katz had attended Husserl's lectures and seminars in Göttingen and eventually came to view Husserl's phenomenology and phenomenological method as indispensable to psychology (Katz 1950: 18). For Katz, the phenomenological method was primarily seeking to offer an undistorted description of the phenomena as they appeared, and this is also how he sought to employ it in his own investigations of touch and colour. In his work on touch, for instance, Katz meticulously distinguished surface touch, immersed touch, and volume touch (Katz 1989: 50-53), thereby pointing to the tactile difference between touching the top of a desk, immersing one's hand in a container with liquid, and feeling an underlying bone fracture by palpating the skin surface. Importantly, Katz was not at all opposed to or disinterested in quantitative research and mainstream psychological theory. Indeed, for Katz, phenomenological psychology was not about avoiding the rigors of experimentation and theory construction. On the contrary, not only might insights and ideas from phenomenology lead to better experiments and better theorizing, but experimental techniques could also be used to refine the phenomenological observations and explorations, and make the findings more reliable and intersubjectively accessible.

\footnotetext{
${ }^{2}$ For some recent influential readings of Husserl's phenomenology, his methodology, his approach to intersubjectivity, etc. see Steinbock 1995, Zahavi 2001, Smith 2003, Zahavi 2003, Overgaard 2004, Hopp 2011, Taipale 2014, Zahavi 2017.
} 
Katz was only one of the first in an illustrious line of phenomenologically inspired psychologists, which also includes figures such as Frederik J.J. Buytendijk (1887-1974) and Erwin Straus (1891-1975). If anything, however, the influence of phenomenology on psychiatry was even more decisive. Consider, for example, the early contributions of Karl Jaspers (1883-1969) who, before his career as an influential existential philosopher, worked as a psychiatrist. Already in 1912, Jaspers published a short article outlining how psychiatry could profit from Husserlian phenomenology (Jaspers 1912). This was followed up one year later when Jaspers published his General Psychopathology. This milestone contribution, which subsequently appeared in many expanded editions, was not only firmly committed to the idea that psychiatry requires philosophical tools and distinctions. It also defended the view that psychiatry has to consider the experiential perspective of the patient if it is to make scientific progress. The book's careful and systematic description of numerous anomalous mental phenomena has had a significant impact on the subsequent development of psychiatry, especially in Germany and the UK. In connection with the centenary of the book, the continuing relevance of many of Jaspers' reflections on the status and nature of psychiatry - especially in light of the controversies surrounding DSM-5 and the RDoC initiative - has been highlighted in a number of recent publications (cf. Stanghellini \& Fuchs 2013, de Leon 2014).

Many prominent psychiatrists in Switzerland, France, and Germany, including, for instance, Binswanger (1881-1966), Minkowski (1885-1972), and Blankenburg (1928-2002) continued this tradition of phenomenological psychiatry. In Minkowski’s work, Lived Time, published in 1933, we find explicit reflections on the question of whether and how one ought to make use of philosophical phenomenology in clinical practice. As Minkowski observes, there are those for whom the term 'philosophical' has pejorative connotations. In his view, however, a use of the phenomenological framework and approach has led to an expansion of psychiatric knowledge by providing some access to the otherwise impenetrable world of the patient (Minkowski 1970: xxxix). At the same time, however, Minkowski also emphasizes how philosophical phenomenology might learn from its engagement with psychiatry and psychopathology. By constantly being oriented towards the concreteness of the patient's experiential life, psychiatry can help steer philosophy away from empty abstractions and speculations. Moreover, psychopathological investigations can also lead to a refinement of the phenomenological analyses, 
insofar as they call attention to specific aspects or dimensions of experience that the philosophers have overlooked.

Minkowski's discussion of the relation between phenomenology and psychopathology is a good illustration of what has later been called a relationship of mutual enlightenment (Gallagher 1997). It is not a question of simply importing and applying ready-made ideas from one side to the other. Rather, both sides can profit from and grow as a result of their interaction. Despite his favourable attitude, Minkowski was, however, not overlooking the difference between philosophy and psychopathology and he explicitly warned against any overly naive take on their compatibility. As he puts it in the preface to the second French printing,

It was never a question of transposing purely and simply the data and methods used by a given philosopher into the realm of psychopathological facts. That would have led inevitably to a 'hyperphilosophizing' of psychopathology, a danger I carefully avoided and against which I warned my young colleagues who were following in my path; it would have risked deforming psychopathology entirely. (Minkowski 1970: xxxix)

The danger that Minkowski is warning against is real. Consider a recent article entitled "Understanding the Key Tenets of Heidegger's Philosophy for Interpretive Phenomenological Research.” More than half of the article is taken up by a presentation of core concepts in Heidegger's philosophy in order to show how “Heidegger's philosophy can 'purely' (and not second hand)" (Horrigan-Kelly, Millar, Dowling 2016: 6) be used to investigate how teenage parents experience the use of family health care services. Most of that presentation is hard to understand - even for professional philosophers, and the article is filled with factual mistakes and odd interpretive claims. ${ }^{3}$

${ }^{3}$ The authors claim, for instance, that Heidegger was a student of Husserl in the years 1909-1911 (2016: 2), and that "being" for Heidegger amounts to those descriptions or accounts that human beings provide of their own ordinary existence (2016: 2). Husserl only took up a position in Freiburg, where Heidegger was based, in 1916. As for Heidegger's concept of being, simply to equate it with our commonsensical self-interpretations, is fundamentally to misunderstand the nature of Heidegger's ontology. 


\section{Naturalized Phenomenology}

The interest in integrating phenomenological philosophy and the empirical study of the mind underwent a marked revival in the early nineties, partially as a result of work by the Chilean neuroscientist Francisco Varela. One of Varela's leading ideas was that cognitive science had to integrate a more phenomenological approach to the study of experience if it ever was to provide a truly scientific theory of consciousness (Varela 1996). Heralding Merleau-Ponty as someone who already early on "argued for the mutual illumination among a phenomenology of direct lived experience, psychology and neurophysiology” (Varela, Thompson, Rosch 1991: 15), Varela went on to propose that phenomenological forms of investigation should be incorporated into the experimental protocols of neuroscientific research on consciousness (Lutz, Lachaux, Martinerie, \& Varela 2002). ${ }^{4}$

Varela's work led to an intense and fruitful debate concerning the relation between phenomenology and cognitive science that continues to this day (Petitot et al. 1999, Zahavi 2004, Gallagher 2005, Thompson 2007, Harney 2015, Winkler 2017). It has, for instance, led to the development of an influential technique called 'the micro-phenomenological interview' that combines qualitative interview, phenomenology, and cognitive science, and which offers concrete suggestions of how to work within such an interdisciplinary framework (Petitmengin 2006). It also led to the launch of the journal Phenomenology and the Cognitive Sciences and has proven influential in the continuing development of other related areas such as research on enactivism and embodied cognition.

For some, the most important insight was the idea that phenomenology could be informed by and in turn influence empirical research. Phenomenology has traditionally investigated various aspects of consciousness, such as perception, imagination, body-awareness, attention, intentionality, social cognition, and self-consciousness, but these topics have also been

4 As previously mentioned, Paley has argued that qualitative researchers influenced by phenomenology have no interest in causal mechanisms. When considering the ambitions and strategies of those pursuing a form of naturalized phenomenology, it should be evident that it is possible to apply phenomenology and still be interested in causal mechanisms. 
investigated by neuroscientists, cognitive psychologists, developmental psychologists, and psychiatrists, and - as has been argued - it would be wrong for phenomenology to simply ignore empirical findings pertaining to these very topics. Empirical science can present phenomenology with concrete findings that it cannot simply ignore but must be able to accommodate; evidence that might force it to refine or revise its own analyses. At the same time, phenomenology might not only offer its own careful descriptions of the explanandum but might also critically illuminate and challenge some of the theoretical assumptions made by empirical science, just as its analyses might inform the way experiments are set up and interviews are conducted (Gallagher \& Zahavi 2012).

Let us in the following provide three concrete examples of how phenomenology has successfully been applied within a clinical and health care context.

\section{Concrete examples}

Let us first briefly return to Giorgi's Descriptive phenomenological method. In terms of more practical guidelines, Giorgi has advocated a multi-step procedure that the researcher should use when analysing the descriptions that have been collected from the participants: The researcher should first read the whole interview in order to get a sense of its overall meaning. At this stage, no analysis should take place. The next step is to divide the description into smaller meaning units. For each of these meaning units, the researcher should then seek to discover, articulate, and explicate its psychological value and significance. In a final step, the researcher should then synthesize the different findings in order to capture the essence of the experience under investigation (A. Giorgi 2009: 128-137, B. Giorgi 2006: 71-73).

Whereas Giorgi provides very detailed instructions regarding the analysis of the transcribed interview, he has far less to say about how the interview is to be conducted. He does note, however, that we should let the participant speak, as long as she is speaking about her experience. If she starts to drift away, and instead begins to theorize about the experience, the interviewer should gently steer the participant back to the description (A. Giorgi 2009: 122). In a subsequent

application of Giorgi's method, we find Beck explaining that the interviewed participants were asked to offer descriptions of their experiences, and that follow up questions were only used "when certain parts of the description seemed to be lacking clarity or depth” (2013: 188-189). 
Presentations like these suggest that the interviewer is assigned a rather passive role in the process. This impression is further supported by a description offered by Amedeo Giorgi's close collaborator Barbro Giorgi, who argues that one of the distinctive characteristics of a phenomenological interview is that the interviewer should refrain from asking any (guiding) questions. She sees this as constituting a major difference to traditional qualitative research. As she explains, traditional research is confronted with the problem of how to ask the right questions. To take her own example, if one wants to investigate school shootings, should one then investigate the perpetrators emotional life, his personality traits, his past history, family relations, the institutional context of the shooting, his socio-political position, ethnicity, religious affiliation or role models? As B. Giorgi then continues, to select between these different options is a daunting choice for the traditional researcher. There is always a danger of making the wrong choice, of asking the wrong questions, and thereby of failing to capture what is truly psychologically significant. The advantage of the phenomenological approach is that it can avoid this challenge:

\begin{abstract}
Allowing the participants to express themselves about their own experience without the influence of the researcher's question sidesteps these problems. If a research participant is asked to describe an actual event that contains the phenomenon under investigation, then the participant will spontaneously contextualize the event and give the most relevant and important aspects of the experience. (B. Giorgi 2006: 81)
\end{abstract}

In our view, B. Giorgi is not only overly optimistic, but also fundamentally misguided in her insistence that the phenomenological interviewer must refrain from asking questions. This handsoff approach, which basically reduces the interviewer to a tape-recorder, is faced with an obvious problem. What if the participants who are being interviewed and who are requested to provide a rich description of, say, what it is like to undergo a panic attack or what it is like to live with a mental illness, offer only coarse and superficial descriptions?

To circumvent that problem, a number of phenomenological psychiatrists have recently adopted a different and, in our view, far more fruitful approach. First a bit of background.

In recent years, there has been an increased focus on early identification and treatment of schizophrenia, since, roughly speaking, the earlier the treatment can start, the better the prognosis (Addington \& Heinssen 2012). Given this focus, there has been a particular interest in the 
occurrence of non-psychotic (i.e., non-hallucinatory and non-delusional) experiential anomalies, since the presence of such anomalies might aid early differential diagnosis. Such anomalies include, for instance, a disturbed self-presence, a sense of being radically different from others, or a fundamental perplexity regarding tacit social norms.

Based on many years of clinical work and drawing explicit inspiration from ideas found in philosophical phenomenology, a group of researchers went on to develop a qualitative and semiquantitative psychometric checklist called EASE (Examination of Anomalous Self-Experience) (Parnas et al. 2005). The checklist was designed to allow for a systematic and comprehensive clinical exploration and assessment of subtle disturbances of subjective experiences. It consists of 57 items in 5 domains, where each item is illustrated through prototypical examples of patients' complaints and self-descriptions. The 5 domains are (i) cognition and stream of consciousness; (ii) self-awareness and presence; (iii) bodily experiences; (iv) demarcation/transitivism; and (v) existential reorientation. Symptoms are rated both as present or absent and on a 5-point (0-4) severity/frequency scale.

Psychiatrists have used the checklist provided by the EASE manual to conduct semistructured interviews and to engage proactively and exploratively with the participants. By asking questions about specific dimensions and structures of experience, they have been able to elicit descriptions from the patients regarding various relevant domains. This includes, for instance, bodily, temporal, and social dimensions, i.e., dimensions that phenomenological philosophers have considered particularly significant.

Results indicate that anomalous subjective experiences, in particular self-disorders and perplexity, are important prognostic indicators and can aid in the identification of those with a high risk for developing schizophrenia (Møller et al. 2011, Nelson et al. 2012). It has also been argued that the study of these early symptoms will not only benefit the patients, since it allows for early detection and therapeutic intervention, but that it will also benefit science, since it will allow for a better comprehension of the core of schizophrenia. As Parnas and Sass have insisted, if one simply focuses on the psychopathology of chronic schizophrenia, one risks being presented with a heterogeneity of diverse symptoms, whose connection and unity can be difficult to ascertain. If one instead through careful interviews examines and describes the experiential abnormalities found in the early pre-morbid and prodromal stages of schizophrenia, one will in a far more 
undiluted manner be presented with the underlying organizing structure - the basic existential alteration - of which the different symptoms are expressions. As Sass and Parnas writes,

a phenomenological understanding of a disturbed overall mode of consciousness [...] may allow one to make sense out of seemingly bizarre actions or beliefs that might otherwise seem completely incomprehensible. One may, for example, come to see how the person's actions or beliefs are in some respect inspired or justified by the kinds of experiences the person is having (Sass and Parnas 2006: 65).

Indeed, as Sass and Parnas have argued self-disorders in particular may be ascribed a pathogenic role, since they arguably underlie and shape the emergence of the later psychotic pathology (Sass and Parnas 2003: 428).

For another example of applied phenomenology, let us consider how phenomenology has recently been used to develop health care strategies, interventions, and solutions for individuals with cerebral palsy. Cerebral palsy is an umbrella term that defines a group of disorders affecting the development of postural and motor control, which occur due to a non-progressive lesion in the developing central nervous system (Bax et al. 2005; Rosenbaum et al. 2007). The standard treatment and intervention include the use of botulinum toxin (botox), orthopaedic surgery, and physio- and occupational therapy. The overall strategy is to reduce activity limitations, participation restrictions, and the personal dependence that characterize cerebral palsy (Barnes 2001, Rosenbaum et al. 2007). Despite extensive work, however, the practical impact of these treatments, strategies, and interventions has been quite limited (Sheean 2001, Pandyan et al. 2005, Scianni et al. 2009). This shortcoming has more recently led to an increasing emphasis on multidisciplinary patient- and family-centred care (Aisen et al. 2011).

But how can we best support persons living with cerebral palsy? As has recently been argued, if we are to offer appropriate care, we first need to understand what it is like to live with cerebral palsy. This is where the phenomenological interview and the theoretical tools of phenomenology can make a difference. In recent studies, phenomenology was used both to elicit detailed descriptions from the interviewed individuals as well as in the subsequent analysis of the data (Sandström 2007; Martiny 2015a, 2015b; Cole et al. 2017). In contrast to the hands-off approach presented above, the interviewer sought to engage collaboratively with the interviewee 
in order to co-generate knowledge about what it means to live with cerebral palsy. In short, it was not assumed that the interviewee was already able to verbalize such knowledge on his or her own and that the task of the interviewer was merely to register everything being said. Rather, the task of the interviewer had more in common with a kind of Socratic midwifery, i.e., it was a question of helping the interviewee obtain new insights of his own.

To enable this co-generation of knowledge, the interviewer 1) adopted an open-minded and empathic attitude in order to establish basic trust with the interviewee, 2) engaged in a continuous self-critical assessment of his or her own preconceptions and biases, and, 3) most importantly, engaged pro-actively with the interviewee in order to elicit relevantly detailed descriptions. For example, the interviewer opened with general questions, such as "Can you describe how you experience living with cerebral palsy in your daily life?” or "How does cerebral palsy express itself in your daily life?” Often, the general questions motivated the participants to offer medical, neuro-physiological, or therapeutic explanations: "My doctor says that the reason why I experience...” or “According to my physiotherapist these experiences arise because....” But these descriptions did not provide the kind of insight that the interviewer was looking for. He therefore persisted with probing questions, which motivated the interviewee to provide more concrete descriptions and reflect on specific situations, e.g., 'grabbing a cup', 'riding a bike', or 'walking down a staircase'. At this point, the bodily experience of living with cerebral palsy came to the forefront. To elicit further detailed descriptions of these experiences, the interviewer then asked open 'how' questions, e.g., “How do you experience your hand when grabbing a cup?”, “How do you experience your body when walking down a staircase?” or "How would you describe the experience of riding a bike?" The interviewer then followed up on the answers to these questions with further fine-grained open 'how' questions, until the participants offered very detailed descriptions of their bodily experience in specific life situations. The collected descriptions were then subjected to an extensive analysis informed by concepts found in classical phenomenology (Høffding \& Martiny 2016).

One important finding from these phenomenological interviews challenges an underlying premise of much existing biomedical research on and healthcare for persons with cerebral palsy. According to the mainstream account of cerebral palsy presented above, the primary challenge of living with cerebral palsy is very much centred around a lack of progress in the development of postural and motor control. But this is not at all how individuals with cerebral palsy describe their 
own daily life. From an outside perspective (i.e., from the perspective of the neuroscientist or health care professional), it might seem as if they experience a recurrent lack of motor control. But from the perspective of the individuals with cerebral palsy, there is no experience of a lack of control. Since cerebral palsy is a congenital neurological disorder, this is how it has always been for them. Whereas an acquired neurological disorder typically involves an experiential 'before and after', i.e., an experienced comparison of what I can do now with what I could before, this is not what we find in the congenital cases of cerebral palsy. Rather, as suggested by the interview analyses, persons with cerebral palsy have typically developed their own forms of body control. Of course, the claim is not that individuals with cerebral palsy do not face many challenges, but the reason why biomedical treatment, protocols, strategies, and interventions have had little success is that they largely ignore the challenges that people with cerebral palsy actually find distressing, such as a fundamental bodily uncertainty rooted in self-doubt, a lack of energy, and pervasive social anxiety (Martiny 2015a).

Based on the interview results, Martiny and Aggerholm collaborated with health care practitioners (psychologists, physiotherapists, and occupational therapists) to develop a multidisciplinary and person-centered form of intervention that could address the experiences of bodily uncertainty in cerebral palsy (Martiny \& Aggerholm 2016, Aggerholm \& Martiny 2017). The phenomenological interview was again used, but this time to assess and evaluate whether the intervention had been successful and made sense for the individuals with cerebral palsy. In short, phenomenology was not only used at the research phase, but also when it came to the practical assessment of the proposed health care solutions.

The last example we briefly want to present concerns a study by nurses of patients with hemispatial neglect after stroke, where particular attention was devoted to an examination of the patient's experience of self, other, and world within the first month following the stroke (Klinke et al. 2015).

Neglect is a multimodal syndrome that often occurs following stroke in the right brain hemisphere (Valler \& Bolognini 2014). It can be observed in the patients’ failure to notice persons or objects located to their left and might be accompanied by anosognosia and somatoparaphrenia, where the patients either deny their disability or deny ownership of their own left-sided limbs. Although it has been studied extensively, many questions remain unanswered, especially concerning the patients' neglect experience and their limited recognition of their own deficits. 
The behaviour of the patients with neglect creates many odd situations in the daily care for all implied parties (patients, health care professionals, and relatives) and the anosognosia makes it difficult to motivate the patients to engage in therapy, thereby preventing effective rehabilitation (Adair \& Barrett, 2008; Bartolomeo, 2014). In order to optimize care, it is crucial to gain better knowledge of how to motivate and encourage the patients to confront and cope with their neglect (Robertson \& Halligan, 1999).

In a recent study, the neglect-related experiences of 12 patients were examined using bedside care, brief informal interviews, extensive clinical observations, and longer opened-ended dialogical interviews (Klinke et al. 2014; Klinke et al. 2015). Importantly, to frame the investigation, the researchers did not merely draw on Husserl's and Merleau-Ponty's classical work on phenomenology of embodiment. They also drew on and consulted some of descriptive analyses and conceptual distinctions that can be found in more recent work at the interface between phenomenology and cognitive science. Using these resources, the researchers set out to investigate the impact of neglect on the perception of affordances, on interpersonal relations and on body awareness (body image and body schema).

Two findings in particular were noteworthy. The first is that none of the patients persistently ignored their left side. Rather, the level of their awareness fluctuated and their neglect behaviour increased with fatigue. Importantly, their left-side awareness could be enhanced and modulated by the presence of emotionally salient stimuli. In one case, for instance, a mother was able to hold her infant baby with her left arm and could also easily mix formula for her baby using her left hand. By contrast, using her left hand to make coffee was much harder for her. These findings suggest that part of the health care strategy should be to use personally significant cues to motivate the patient to reconquer the neglected space.

The second finding is that the patients' reluctance to share the odd neglect experiences with others were often due to the fact that they lacked a proper vocabulary to describe their unusual experiences. After having participated in the study, the patients reported that their condition had improved, precisely because it was now easier for them to articulate and communicate their experiences to others and thereby receive relevant feedback. Being increasingly understood by others, gave them feelings of relief and also made the neglect experiences less frightening and disturbing. Care for neglect patients should therefore include strategies that aim at facilitating the expression and communication of the neglect experiences. With the increasing insight into their 
own condition, the patients face a period of vulnerability, however. It is therefore also crucial for health care professionals to demonstrate an awareness and understanding of these challenges, and to help both the patient and their close relatives tackle them as they arise (Klinke et al. 2015).

Summing up, phenomenology can play a significant role in diagnosis, treatment, and therapy. Using phenomenology in a clinical context is not merely a question of being interested in the particular perspective of the patient. Part of the task is precisely to apply a mindset and a theoretical framework that will allow one to capture the fundamental structures of the changed life situation. How is your very being-in-the-world transformed if you are living with schizophrenia, cerebral palsy, or hemispatial neglect? How does the illness, disability, or disorder affect the subject's relation to itself, to the world, and to others?

\section{Conclusion}

Phenomenologically informed qualitative research has different aims than phenomenological philosophy, but it is questionable whether the former can qualify as phenomenological if it either ignores or misinterprets the latter. Anybody who claims to be endorsing a phenomenological method, procedure, or approach should have some familiarity with phenomenological theory. At the same time, however, we should not make the same mistake as Horrigan-Kelly, Millar, and Dowling. When applying phenomenology, we shouldn't 'hyper-philosophize'.

In the existing qualitative research literature, a lot of ink has been spilled on the question of how the researcher should employ Husserl's epoché and reduction. An initial challenge has been to understand what exactly Husserl was up to. Whereas van Manen has insisted that Husserl's aim was to gain insight into "the phenomenality of lived experience" (2017a: 779), and while Langdridge writes that Husserl sought to “take a 'God’s eye view’ on experience” (2008: 1129), Gaudet and Robert have recently argued that Husserl's aim was to “adopt a point of view 'from nowhere'” and erase his own presence from the analytical work, for which reason his pursuit is similar to that of the positivists (2018: 45). All of these interpretations are fundamentally mistaken.

Here is our surprising advice. Qualitative researchers should forget about getting the epoché and the reduction right, since those methodological steps strictly speaking are irrelevant for the purpose at hand. In a Husserlian context, both notions are explicitly connected to very specific philosophical aims and pursuits. They are essential parts of Husserl's transcendental 
philosophical project (see Zahavi 2017, 2019, in press). Briefly put, their purpose is to liberate us from a certain natural dogmatism, where we simply take the world for granted, in order thereby to make it possible to address a number of fundamental epistemological and metaphysical questions. For Husserl, it is only by effectuating the epoché and by carrying out the reduction that the (philosophical) phenomenologist can accomplish his main, if not sole, concern, namely to transform "the universal obviousness of the being of the world-for him the greatest of all enigmas-into something intelligible” (Husserl 1970: 180). Ultimately, Husserl would argue that the performance of the epoché and reduction can make us aware of our own constitutive contribution, make us aware of the extent to which our own subjective accomplishments are at play when worldly objects appear in the way they do and with the validity and meaning that they have, and thereby make us realize that subjectivity, reason, truth, and being are essentially interlinked (Husserl 1982: 340). These are important transcendental philosophical ideas. It is much less obvious that they are also ideas that everybody seeking to apply phenomenology outside of philosophy must constantly bear in mind.

There are other features of philosophical phenomenology that are far more relevant to the qualitative researcher. Consider, for instance, phenomenology's criticism of scientism and its recognition of the importance of the lifeworld. Its insistence on developing an open-minded and non-biased attitude. Its careful analysis of human existence, where the subject is understood as an embodied and socially and culturally embedded being-in-the-world. In a non-philosophical context, what is of importance is not whether the phenomenological research or practice adheres strictly to Husserl's (or Heidegger's or Merleau-Ponty's etc.) cursory instructions about how to develop a non-philosophical phenomenology. Of far more importance is whether the application in question allows for new insights or better therapeutic interventions, i.e., whether it makes a valuable difference to the scientific community and/or the clients.

In The Descriptive Phenomenological Method in Psychology, Giorgi offers a concrete example of how his method is to be used. The example concerns the experience of jealousy, and after spending 30 pages detailing in extenso how two solicited descriptions are to be analysed using his multi-step procedure, Giorgi ends up concluding that a subject experiences jealousy "when she discovers a strong desire in herself to be the center of attention of a significant other, or others, that is not forthcoming even though such attention would require irrational conditions” or alternately that jealousy is experienced when the subject "perceives that another is receiving 
significant attention that she wishes were being directed to her and the attention the other is receiving is experienced as a lack in her" (Giorgi 2009: 167). We wonder whether this kind of result really does justice to Giorgi's method, but as it stands, it hardly provides a very convincing justification for the adoption of a complex method. As should be clear from the three examples we have presented above, however, when applied in a creative and productive manner, phenomenology is certainly in a position to offer far more informative and illuminating analyses. Consider, more generally, how a health care professional by drawing on notions such as intentionality, the lived body, sense of agency, empathy, spatiality or temporality might be able to illuminate how different dimensions of human existence are affected in pathology, illness or difficult life-circumstances. When assessing the value of the method, we should in short not primarily be concerned with its orthodoxy, but rather with the results it delivers.

As has been amply demonstrated over the years, phenomenology can not only make a difference in the handling, analysis, and interpretation of the available data, but also, in how the data are obtained in the first place, for instance, through special interview techniques. Our main message to nursing scholars interested in phenomenology is, consequently, the following. You should start to look beyond the different proposals currently found within the qualitative research literature. Not because there is not already good work to be found there, but because there are plenty of untapped resources to be found elsewhere. Relevant resources that should not be ignored include classical phenomenological psychology, classical and contemporary phenomenological psychiatry, and contemporary discussions of naturalized phenomenology. They all offer examples of successful applications of phenomenology; applications that can offer substantial theoretical and methodological support to qualitative researchers. The way forward for anybody interested in the practical application of phenomenology is to draw on and learn from all the available resources. If qualitative researchers and nursing scholars join forces with philosophers, psychiatrists, and cognitive scientists everybody will profit.

\section{FUNDING}

No external funding

\section{ACKNOWLEDGMENTS}


Thanks to Simon Høffding and especially Anthony Fernandez for various helpful comments.

\section{REFERENCES}

Adair, J. C., \& Barrett, A. M. (2008). Spatial neglect: Clinical and neuroscience review. Annals of the New York Academy of Sciences, 1142(1), 21-43.

Addington, J., Heinssen, R. (2012). Prediction and prevention of psychosis in youth at clinical high risk. Annual review of clinical psychology 8: 269-289.

Aggerholm, K., \& Martiny, K.M.M. (2017). Yes We Can! A Phenomenological Study of a Sports Camp for Young People With Cerebral Palsy. Adapted Physical Activity Quarterly, 34(4), 362381.

Aisen, M. L., Kerkovich, D., Mast, J., Mulroy, S., Wren, T. A., Kay, R. M., \& Rethlefsen, S. A. (2011). Cerebral palsy: clinical care and neurological rehabilitation. The Lancet Neurology, 10(9), 844-852.

Barnes M.P. (2001). An overview of the clinical management of spasticity. In Barnes M. P. \& Johnson G.R. (eds.), Upper motor neuron syndrome and spasticity: Clinical management and neurophysiology. Cambridge: Cambridge University Press, $1-11$.

Bartolomeo, P. (2014). Attention disorders after right brain damage. London: Springer.

Bax, M. et al. (2005). Proposed definition and classification of cerebral palsy. Developmental Medicine \& Child Neurology, 47, 571-6.

Bax, M. (2007). Definition and classification of cerebral palsy. From syndrome toward disease. Developmental Medicine \& Child Neurology Suppl, 109, 39-41.

Beck, T.J. ( 2013 ). A phenomenological analysis of anxiety as experienced in social situations. Journal of Phenomenological Psychology, 44, 179-219.

Cole J, Inahara M and Peckitt M. (2017) First Person Accounts of Cerebral Palsy; Adding Phenomenological to Medical and Social Models of Chronic Conditions. Journal of Neurogenetics and Research 1/1: 1002.

De Leon, J. (2014). DSM-5 and the Research Domain Criteria: 100 Years after Jaspers General Psychopathology. American Journal of Psychiatry 171/5: 492-494. 
Gallagher, S. (1997). Mutual enlightenment: recent phenomenology in cognitive science. Journal of Consciousness Studies 4(3): 195-214.

Gallagher, S. (2005). How the body shapes the mind. New York: Oxford University Press.

Gallagher, S., and Zahavi, D. (2012). The Phenomenological Mind, $2^{\text {nd }}$ edn. London: Routledge.

Gaudet, S. \& Robert, D. (2018). A journey through qualitative research: From design to reporting. London: Sage.

Giorgi, B. (2006). Can an empirical psychology be drawn from Husserl's phenomenology? In Ashworth, P.D., Chung, M.C. (eds.): Phenomenology and Psychological Science: Historical and Philosophical Perspectives (pp. 69-88). New York: Springer.

Giorgi, A. (2009). The descriptive phenomenological method in psychology: A modified Husserlian approach. Pittsburgh: Duquesne University Press.

Harney, M. (2015). Naturalizing phenomenology - a philosophical imperative. Progress in Biophysics and Molecular Biology 119/3: 661-669

Høffding, S., \& Martiny, K.M.M. (2016). Framing a phenomenological interview: what, why and how. Phenomenology and the Cognitive Sciences, 15(4), 539-564.

Hopp, W. (2011). Perception and Knowledge: A Phenomenological Account. Cambridge: Cambridge University Press.

Horrigan-Kelly, M., Millar, M., Dowling, M. (2016). Understanding the key tenets of Heidegger's philosophy for interpretive phenomenological research. International Journal of Qualitative Methods doi.org/10.1177/1609406916680634

Husserl, E. (1970). The Crisis of European Sciences and Transcendental Phenomenology: An Introduction to Phenomenological Philosophy, trans. D. Carr. Evanston, IL: Northwestern University Press.

Husserl, E. (1982). Ideas pertaining to a pure phenomenology and to a phenomenological philosophy. First Book. General introduction to a pure phenomenology, transl. F. Kersten. The Hague: Martinus Nijhoff. 
Jaspers, K. (1912). Die phänomenologische Forschungsrichtung in Psychopathologie. Zeitschrift für die gesamte Neurologie und Psychiatrie 9: 391-408.

Jaspers, K. (1963) [1913]. General Psychopathology, trans. J. Hoenig \& M.W. Hamilton. Manchester: Manchester University Press

Katz, D. (1950) [1944]. Gestalt Psychology, trans. R. Tyson. New York: Ronald Press.

Katz, D. (1989) [1925]. The World of Touch, trans. L.E. Krueger. Hillsdale, N.J.: Lawrence Erlbaum Associates.

Katz, D. (1999) [1935]. The World of Colour, trans. R. B. MacLeod \& C.W. Fox. Abingdon: Routledge.

Klinke, M. E., Thorsteinsson, B., \& Jonsdottir, H. (2014). Advancing phenomenological research: Applications of 'body schema,' 'body image,' and 'affordances' in neglect. Qualitative Health Research, 24, 824-836.

Klinke, M.E., Zahavi, D., Hjaltason, H., Thorsteinsson, B., Jónsdóttir, H. (2015). 'Getting the left right': The experience of hemispatial neglect after stroke. Qualitative Health Research 25/12, 1623-1636.

Langdridge, D. (2008), Phenomenology and critical social psychology: Directions and debates in theory of research. Social and Personality Psychology Compass 2/3: 1126-1142.

Lutz, A., Lachaux, J.-P., Martinerie, J., and Varela, F. J. (2002). Guiding the study of brain dynamics by using first-person data: synchrony patterns correlate with ongoing conscious states during a simple visual task. Proceedings of the National Academy of Sciences 99 (3): 1586-91.

Martiny, K. M. M. (2015a). Embodying Investigations of Cerebral Palsy: A Case of Open Cognitive Science. Doctoral dissertation. Copenhagen: University of Copenhagen.

Martiny, K.M.M. (2015b). How to develop a phenomenological model of disability. Medicine, Health Care and Philosophy, 18(4), 553-565.

Martiny, K.M.M., \& Aggerholm, K. (2016). Embodying cognition: working with self-control in cerebral palsy. The Cognitive Behaviour Therapist, 9.

Minkowski, E. (1970). Lived Time: Phenomenological and Psychopathological Studies, trans. N. Metzel. Evanston: Northwestern University Press. 
Møller, P., Haug, E., Raballo, A., Parnas, J., Melle, I. (2011). Examination of anomalous selfexperience in first-episode psychosis: interrater reliability. Psychopathology 44: 386-390.

Nelson, B., Thompson, A., \& Yung, A. R. (2013). Not all first-episode psychosis is the same: Preliminary evidence of greater basic self-disturbance in schizophrenia spectrum cases. Early Intervention in Psychiatry 7(2): 200-204.

Overgaard, S. (2004). Husserl and Heidegger on Being in the World. Dordrecht: Kluwer Academic.

Paley, J. (1997). Husserl, phenomenology and nursing. Journal of advanced nursing 26, 187-193

Paley, J. (2005). Phenomenology as Rhetoric. Nursing Inquiry 12(2): 106-116.

Paley, J. (2013). 5 Questions. In A. Forss, C. Ceci, J.S. Drummond (eds.): Philosophy of Nursing: 5 Questions (pp. 143-155). Copenhagen: Automatic Press.

Paley, J. (2017). Phenomenology as qualitative research: A critical analysis of meaning attribution. London: Routledge.

Pandyan A.D. et al. (2005). Spasticity: clinical perceptions, neurological realities and meaningful measurement. Disability and Rehabilitation, 27, 2-6.

Parnas, J., Møller, P., Kircher, T., Thalbitzer, J., Jansson, L., Handest, P., and Zahavi, D. (2005). EASE: examination of anomalous self-experience. Psychopathology 38: 236-58.

Petitmengin, C. (2006). Describing one's subjective experience in the second person: an interview method for the science of consciousness. Phenomenology and the Cognitive Sciences 5: 229-69.

Petitot, J., Varela, F. J., Pachoud, B., and Roy, J.-M. (eds.) (1999). Naturalizing Phenomenology Stanford, Calif.: Stanford University Press.

Petrovskaya, O. (2014), Nursing Phenomenology after Paley. Nursing Philosophy, 15: 60-71

Robertson, I. H., \& Halligan, P. W. (1999). Spatial neglect: A clinical handbook for diagnosis and treatment. Hove, UK: Psychology Press.

Rosenbaum, P. et al. (2007). A report: the definition and classification of cerebral palsy April 2006. Developmental Medicine and Child Neurology, 109 (suppl 109), 8-14. 
Sandström, K. (2007). The lived body-experiences from adults with cerebral palsy. Clinical Rehabilitation, 21, 432-441.

Sass, L. and Parnas, J. (2003). Schizophrenia, consciousness, and the self. Schizophrenia Bulletin 29: 427-444.

Sass, L.A. and Parnas, J. (2006). Explaining schizophrenia: the relevance of phenomenology. In Chung, M.C., Fulford, K.W.M., Graham, G. (eds.): Reconceiving Schizophrenia (pp. 63-95). Oxford: Oxford University Press.

Scianni, A., Butler J. M., Ada L., Teixeira-Salmela L.F. (2009) Muscle strengthening is not effective in children with cerebral palsy: a systematic review. Australian Journal of Physiotherapy 55: 81-87]

Sheean, G. (2001). Botulinum toxin treatment of spasticity: Why is it so difficult to show a functional benefit? Current Opinion in Neurology, 14:771 - 776.

Smith, A. D. (2003). Routledge Philosophy Guidebook to Husserl and the Cartesian Meditations. London: Routledge.

Spiegelberg, H. (1972). Phenomenology in Psychology and Psychiatry: A Historical Introduction. Evanston: Northwestern University Press.

Stanghellini, G. \& Fuchs, T. (eds.) (2013). One Century of Karl Jaspers' General Psychopathology. Oxford. Oxford University Press.

Steinbock, A. (1995). Home and Beyond. Generative Phenomenology after Husserl. Evanston, IL: Northwestern University Press.

Taipale, J. (2014). Phenomenology and Embodiment: Husserl and the Constitution of Subjectivity. Evanston, Ill.: Northwestern University Press.

Thompson, E. (2007). Mind in Life: Biology, Phenomenology, and the Sciences of Mind. Cambridge, Mass.: Harvard University Press.

Valler, G., \& Bolognini, N. (2014). Unilateral spatial neglect. In A. C. Nobre \& S. Kastner (Eds.), The Oxford handbook of attention (pp. 972-1027). Oxford, UK: Oxford University Press.

van Manen, M. (2017), But is it phenomenology? Qualitative Health Research 27/6: 775-779. 
Varela, F. J. (1996). Neurophenomenology: a methodological remedy for the hard problem. Journal of Consciousness Studies 3(4): 330-49.

Varela, F. J., Thompson, E., and Rosch, E. (1991). The Embodied Mind: Cognitive Science and Human Experience. Cambridge, Mass.: MIT Press.

Watson, R. (2017). Phenomenology as qualitative research: A critical analysis of meaning attribution John Paley (2016), Routledge, ISBN-13: 978-1138652811. Nursing Philosophy, 18(4), e12180. doi:10.1111/nup.12180

Winkler, R. (ed.) (2017). Phenomenology and Naturalism. London: Routledge.

Zahavi, D. (2001). Husserl and Transcendental Intersubjectivity, trans. E. Behnke. Athens: Ohio University Press.

Zahavi, D. (2003). Husserl's Phenomenology. Stanford: Stanford University Press.

Zahavi, D. (2004). Phenomenology and the project of naturalization. Phenomenology and the Cognitive Sciences 3(4): 331-47.

Zahavi, D. (2017). Husserl's Legacy: Phenomenology, Metaphysics, and Transcendental Philosophy. Oxford: Oxford University Press.

Zahavi, D. (2018). Getting It Quite Wrong: Van Manen and Smith on Phenomenology. Qualitative Health Research. Online first https://doi.org/10.1177/1049732318817547

Zahavi, D. (2019). Phenomenology: The Basics. London: Routledge.

Zahavi, D. (in press). Applied phenomenology: Why it is safe to ignore the epoché. Continental Philosophy Review 